\title{
Gazelle Eye like Facial Melanosis (Clinico-Histopathological Study)
}

Khalifa E Sharquie ${ }^{1,2^{*}}$ and Adil A Noaimi ${ }^{1,2}$

${ }^{1}$ Scientific Council of Dermatology and Venereology-Iraqi and Arab Board for Medical Specializations, Iraq

${ }^{2}$ Department of Dermatology and Venereology, College of Medicine, University of Baghdad, Baghdad, Iraq

*Corresponding author: Khalifa E Sharquie, Department of Dermatology and Venereology, College of Medicine, University of Baghdad, Medical Collection Office, P.O. Box 61080 Postal Code 12114, Baghdad, Iraq, Tel: 009647901468515; Fax: 009641-5372193; E-mail: ksharquie@ymail.com

Rec date: May 03, 2014; Acc date: June 02, 2014; Pub date: June 04, 2014

Copyright: (c) 2014 Sharquie KE, et al. This is an open-access article distributed under the terms of the Creative Commons Attribution License, which permits unrestricted use, distribution, and reproduction in any medium, provided the original author and source are credited.

\begin{abstract}
Background: There are many causes of facial melanosis like melasma, frictional melanosis, acanthosis nigricanis, lichen planus actinicus, and others. But Gazelle eye like facial melanosis was not recognized as a special disease with characteristic features.
\end{abstract}

Objective: To report a new recognized facial pigmentation that is not uncommonly seen among adults especially females which is locally known as a Gazelle eye like facial melanosis.

Patients and methods: This case series descriptive study with histopathological examination was conducted in the Department of Dermatology, Baghdad Teaching Hospital; Baghdad, Iraq during the period from January 2009December 2013. One hundred patients with gazelle eye like facial pigmentation were collected and evaluated by clinical and histopathological examinations. History was obtained from each patient regarding all socio- demographic aspects related to the disease. Also, clinical assessment was done including Wood's light examination. Incisional or punch biopsy was performed from 10 patients for histopathological examination.

Results: One hundred patients were recorded and examined: $88(88 \%)$ females and $12(12 \%)$ males with a female to male ratio: $6.5: 1$. Their ages ranged from 16-48 $(28.7 \pm 5)$ years. The duration of the disease ranged from $5-15(8 \pm 3.2)$ years. All patients had characteristic pigmentation that started around the eyes in a symmetrical fashion and descended down to the cheeks which ended with a tail like and there was a well demarcated white band across the cheek's pigmentation. The pigmentation was dark brown in color that is not delineated from surrounding normal face skin with negative Wood's light examination. Histopathological study revealed mainly dermal melanosis as many melanophages were seen in the superficial dermis with basal melanosis of the epidermis. On systemic review all patients were apparently healthy apart from facial melanosis as the main complaint.

Conclusions: We think this is a new entity that commonly seen in the clinical practice as a cause of facial melanosis but it's not well recognized. It has a characteristic location, distribution and configuration that deserve the name "Gazelle eye like facial melanosis".

Keywords: Gazelle eye; Facial melanosis; Pigmentation; Dermal melanosis

\section{Introduction}

Facial melanosis is a major cosmetic problem among people especially in people dark complexion $[1,2]$, and from daily clinical practice we can categorize the commonest causes of facial melanosis as follow [1-3]:

1-Melasma: It is probably the commonest cause of facial pigmentation and it has a characteristic light to dark brown color with stuck up on appearance [1-8]. It could be defined as chronic disfiguring dermatological disease of females and males, although much more common among females that appear during the active reproductive period with the presence of provoking factors like hormonal changes and sunlight that induce brown hyperpigmentation of the face .This may take many shapes but much more commonly a butterfly and a mask appearance [6-13].
2- Frictional Melanosis: As there is a common habit among people to do rubbing and friction of their face in order to induce whitening of the skin [14] but overtime there is a reactionary hypermelanosis of the epidermis and dermis that appeared clinically as a deep dark brown in color $[14,15]$. The pigmentation localized mainly over the bony areas of the face usually on the temples, forehead, and cheeks and around the mouth [13-15].

3-Lichen Planus Actincus (butterfly like pigmentation): Is also one of the commonest causes of facial melanosis especially in chronic cases and might resemble melisma [16-18]. It affects young females and males and appears as a dark brown pigmentation with violaceous hue which is distributed on the butterfly area of the face: cheeks, nose, around the eye brows with or without scattered typical papules of lichen planus [1-3]. While the histopathological picture is typical for lichen planus like: basal liquefaction, band like lymphocytic infiltrations of the dermal layer with melanophages [1-3,16-18].

4-Acanthosis Nigricans: Acanthosis nigricans of the face which could be localized to the face only or part of the generalized ordinary acanthosis nigricans. The skin is darkly pigmented thickened 
hyperkeratotic that usually affects the cheeks, around the eyes and forehead with or without skin tags. The histopathological features are that of acanthosis nigricans [19-24].

5-Postinflammatory Hyperpigmentation: Any inflammatory skin lesion that affects the face can be complicated by hypermelanosis as it resolves like: eczema, contact dermatitis, acne, lupus erythematous etc. $[1-3,13,25]$.

6-Miscellaneous: Phytodynamic dermatitis, Riehls melanosis, Naevus of Ota, drug induced hypeperpigmentation, and others [1-3,25-29].

In addition there is not uncommon facial pigmentation that is locally known as Gazelle eye like facial melanosis that is commonly encountered in clinical practice but often misdiagnosed and commonly confused with melasma and does not respond to ordinary therapy options for melasma [1-3,6,8-14].

And after extensive searching in the medical literatures, we didn't find a report about this type of facial pigmentation.

For this reason, the present work was arranged to evaluate this new unrecognized cause of facial pigmentation by doing clinical and histopathological studies.

\section{Patients and methods}

This is a case series descriptive and histopathological study that was conducted in the Department of Dermatology, Baghdad Teaching Hospital, Baghdad; Iraq during the period from January 2009-October 2013. One hundred patients with Gazelle eye like facial pigmentation were included in this work.

History was obtained from each patient regarding all sociodemographic aspects related to the disease including: age, age of onset, gender, duration of disease, previous medical history, drugs ingestion, hair epilation, history of friction, seasonal variation, menstrual cycle, marital status, pregnancy and hormonal intake, history of using sun block agents, marital status, occupation and family history of the same condition.

Clinical assessment was done regarding the following points: site, symmetry, border, color, size of lesions and morphological picture. Systemic evaluation for all patients was performed to exclude any underlying internal causes. All patients were examined with Wood's light to differentiate whether it is dermal or epidermal or mixed melanosis. All patients had Fitzpatrick's skin type III and IV. Incisional or punch biopsy was performed from 10 patients for histopathological evaluation after processing with Hematoxyllin and Eosin and Fontana masson stains.

Formal consent was taken from each patient after full explanation about the goal and nature of the present study, the nature of the disease, course, and the need for photographs. Also, ethical approval was performed by the Scientific Council of Dermatology and Venereology-Iraqi Board for Medical Specializations.

All patients were photographed by Sony-Cyber Digital, high sensitivity, 16.1 megapixels, $5 \mathrm{x}$ optical zoom camera, in the same place with fixed illumination and distance.

\section{Results}

A total of 100 patients with periorbital hypermelanosis with cheek extension (Gazelle eye like facial pigmentation) were seen. There were
$88(88 \%)$ females and $12(12 \%)$ males with a female to male ratio: 6.5:1 .Their ages ranged from 16-48 years with a mean \pm SD of $28.7 \pm 5$ years. The duration of the disease ranged from 5-15 years with a mean $\pm \mathrm{SD}$ of $8 \pm 3.2$ years. While the age of onset was ranged from 13-40 years with a mean \pm SD of $21.2 \pm 4$ years.

Regarding the age of onset of the disease were as follow: in 40(405) patients between 10-19 years, 43(43\%) patients between 20-29 years while in $17(17 \%)$ patients developed between $30-39$ years. While the age distribution of patients was as follow as follow: 20(20\%) patients had the disease between $10-19$ years, $43(43 \%)$ between $20-29$ years, $20(20 \%)$ patients between $30-39$ years while in $17(17 \%)$ had between 40-50 years.

Family history of the same condition was positive in $37(36 \%)$ patients (4 males and 33 females). Negative history of the following factors: friction, drugs or pregnancy, oral contraceptive pills, seasonal variation. No effect of the hair epilation and using sun block agents in remission or exacerbation of the condition. No difference regarding the aggravating factors between married versus unmarried females. Also On systemic review all patients were apparently healthy apart from facial pigmentation of face as the main complaint of these patients.

Many of assumed provoking factors such as: fatigue was seen in $86(86 \%)$ patients, sunlight in $70(70 \%)$ patients.

All patients mentioned that the disease was recalcitrant to all standard optional therapies for melasma like bleaching agents.

All patients had characteristic pigmentation that started around the eyes periorbital hyperpigmentation in very close symmetrical fashion and descended down to the cheeks which ended with a pointed tail like configuration. Also, there was a well demarcated linear white band across the middle cheek's pigmentation that divided the pigmentation in two parts (Figures 1-4).

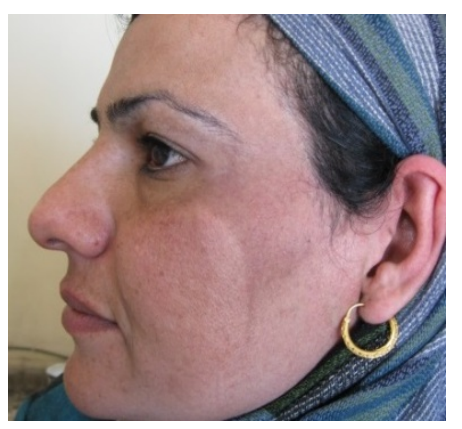

Figure 1: Thirty five years old female with Gazelle eye like facial melanosis with characteristic periorbital pigmentation and cheeks extension.

The pigmentation was uniform even and not well demarcated from normal surrounding face skin and it was dark brown in color with negative Wood's light examination in all cases.

The histopathological study showed basal melanosis in the epidermis and dermal melanosis in a form of numerous melanophages seen in the superficial dermis in the H/E stain (Figure 5A). While the Fontana masson stain section showed also basal melanosis of the epidermis and dermal melanosis (Figure 5B). 
Citation: Sharquie KE, Noaimi AA (2014) Gazelle Eye like Facial Melanosis (Clinico-Histopathological Study). Pigmentary Disorders 1: 111. doi: 10.4172/jpd.1000111

Page 3 of 4

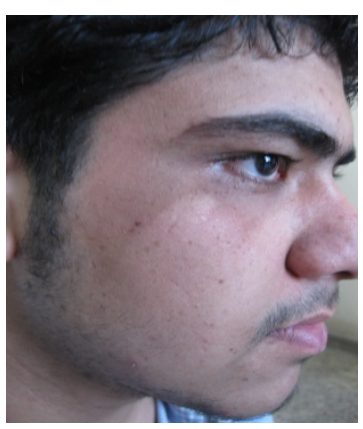

Figure 2: Twenty five years old male with Gazelle eye like facial melanosis.

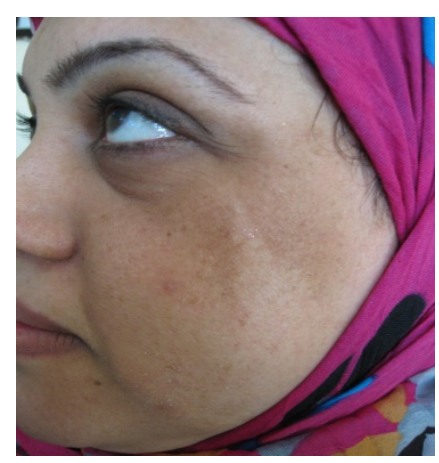

Figure 3: Thirty eight years old female with Gazelle eye like facial melanosis.
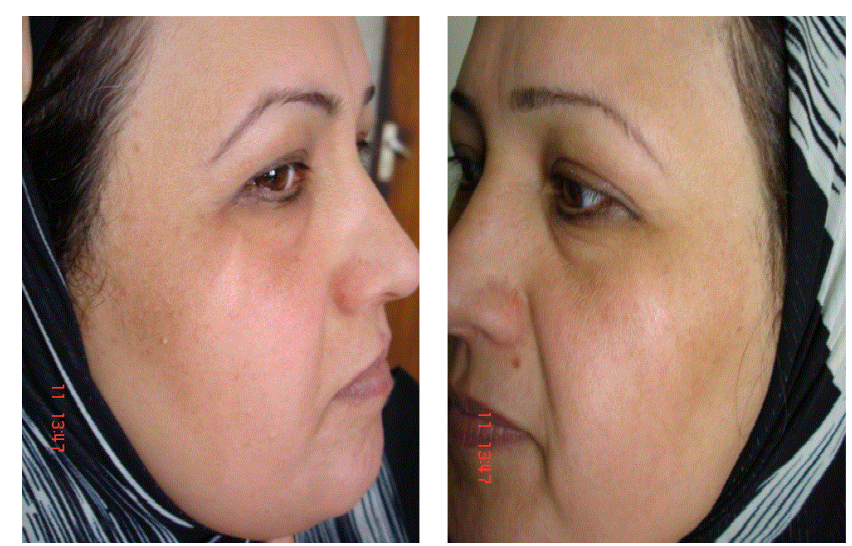

Figure 4: Forty years old female with Gazelle eye like facial melanosis.

\section{Discussion}

Gazelle eye like facial melanosis although is not un common pigmentory problems among Iraqi population but unfortunately often confused and mixed up either with melasma especially dermal type [1-13] or with frictional melanosis [13-15].
The present study had shown that this entity has many characteristic features that could be differentiated from other causes of facial melanosis:

1. It has characteristic distinguishing location mainly the periorbital region and cheeks in a symmetrical fashion.

2. In contrast with what has been mentioned about periobital pigmentation only, gazelle eye like mostly occurs below ten years and increases in puberty and with age [1-3,13].

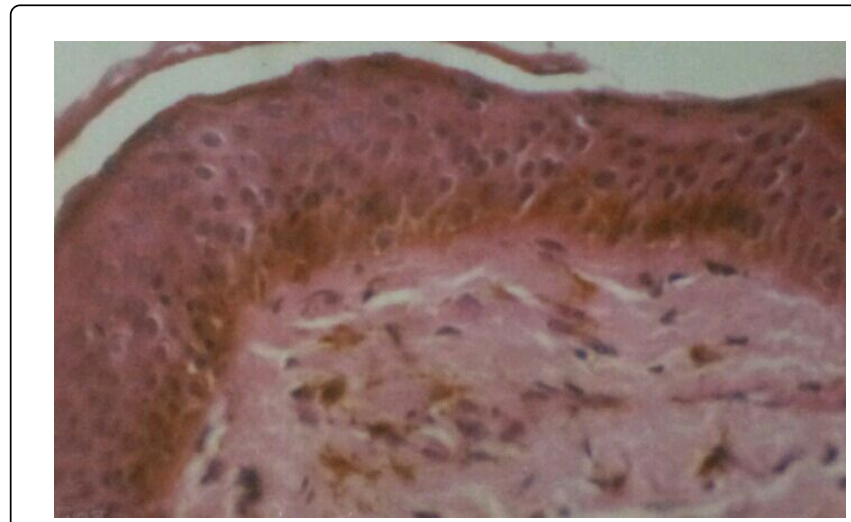

Figure 5A: Biopsy from patient with Gazelle eye like facial melanosis stained by H\&E stain, showing basal hypermelanosis with numerous dermal melanophages (original magnification $x$ $40)$.

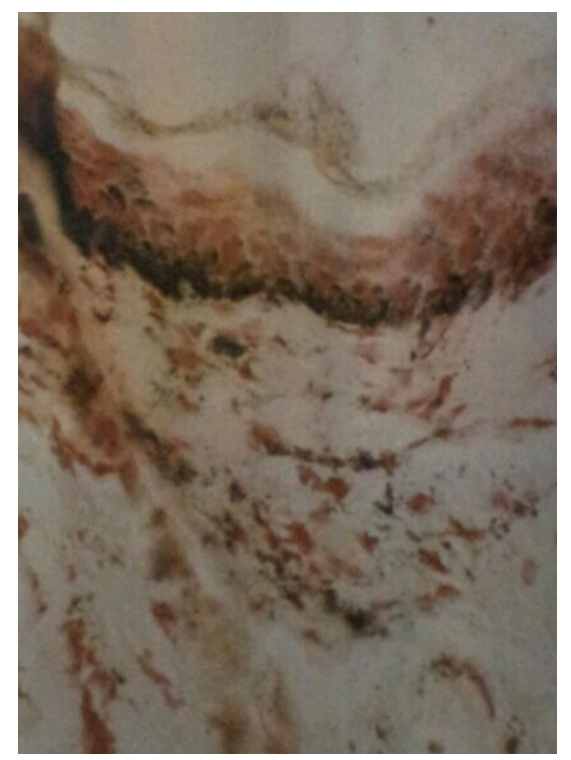

Figure 5B: Fontana masson stain, showing basal and superficial dermal melanosis (original magnification $\times 40$ ).

3. It has distinctive morphological features as it has a well demarcated linear band of hypopigmentation in the middle of the cheeks pigmentation and it extends downward as a pointed tail like configuration. 
4. The pigmentation was always dark-brown with no distinct demarcation from the surrounding normal face. Wood,s light examination showed no contrast seen in all patients which does indicate dermal melanosis.

5. The histopathological pictures are mostly dermal melanosis.

6. There are no hormonal effects by menstrual period, pregnancy and contraceptive pills.

7. It is often not affected by sunlight exposure like melasma and lichen planus actincus and doesn't respond to routinely topical bleaching therapies [16-18,29].

The aetiopathogenesis of this pigmentation could not be well elaborated but as this disease appears in adult life, in addition to positive family history among other family member, these might suggest that this disease could have genetic and racial elements involved in its pathogenesis.

The management of this type of facial pigmentation is often very difficult as all bleaching agents might give only temporary relieving effects [1-3,6-14,16].

Accordingly, we suggest doing deep dermabrasion as an effective mode of therapy for this condition similar to the dermabrasion that could be carried out for dermal melasma which is resistant to the standard treatments [29].

Also, one of the targets of this work is to stimulate other dermatologists in other countries to observe this type of pigmentation and to be reported.

In conclusion, Gazelle eye like facial melanosis is a distinctive clinical and pathological entity that has many characteristic features.

\section{References}

1. Anstey AV (2010) Disorders of Skin Colour. Rook's Textbook of Dermatology. (8thedn). Wiley-Blackwell Publishing Company, Singapore, 58:2923-2982.

2. Chang MW (2012) Disorders of Hyperpigmentation. Dermatology Jean L Bolognia. (3rdedn). ELSEVER SAUNDRES 1052-1053.

3. Pandya AG, Guevara IL (2000) Disorders of hyperpigmentation. Dermatol Clin 18: 91-98, ix.

4. Sharquie KE, Al-Hamdi KI (1989) Melasma in Iraq: Clinical and epidemiological study. A Diploma Dissertation in Dermatology and Venereology, College of Medicine, University of Baghdad.

5. Sharquie KE, Al-Dahir SA (2000) Melasma in Iraqi women: A clinical; \& histopathological \& histochemical study. J Pan-Arab League Dermatol 11: 111-117.

6. Sharquie KE, Daher SA (2002) Treatment of Melasma in Iraqi women with a new topical formula (Hydroquinone $2 \%$, Honey $75 \%$ \& Aqua Rosa 23\%). Iraqi J Comm Med 15: 42-46.

7. Sharquie KE (1987) Monomethyl ether of hydroquinone as a possible cause of vitiligo in patients with melasma. Iraqi Med J 35: 49-51.

8. Sharquie KE, Al-Tikreety MM, Al-Mashhadani SA (2005) Lactic acid as a new therapeutic peeling agent in melasma. Dermatol Surg 31: 149-154.

9. Sharquie KE, Al-Tikreety MM, Al-Mashhadani SA (2006) Lactic acid chemical peels as a new therapeutic modality in melasma in comparison to Jessner's solution chemical peels. Dermatol Surg 32: 1429-1436.
10. Sharquie KE, Al-Mashhadani SA, Salman HA (2008) Topical 10\% zinc sulfate solution for treatment of melasma. Dermatol Surg 34: 1346-1349.

11. Rigopoulos D, Gregoriou S, Katsambas A (2007) Hyperpigmentation and melasma. J Cosmet Dermatol 6: 195-202.

12. Rashid SA (2003) Efficacy and safety of topical ammoniated mercury in melasma. Thesis for Fellowship of Iraqi Board for Medical Specializations in Dermatology and Venereology.

13. Khanna N, Rasool S (2011) Facial melanoses: Indian perspective. Indian J Dermatol Venereol Leprol 77: 552-563.

14. Sharquie KE, Noaimi AA (2013) How to bring beauty back.13th international Pan League of Dermatology Conference.

15. Al-Aboosi M, Abalkhail A, Kasim O, Al-Khatib A, Qarqaz F, et al. (2004) Friction melanosis: a clinical, histologic, and ultrastructural study in Jordanian patients. Int J Dermatol 43: 261-264.

16. Sharquie KE, Ahmad EM (1991) Lichen planus actinicus: Clinical and histopathological study. A Diploma Dissertation in Dermatology and Venereology, College of Medicine, University of Baghdad.

17. James WD, Berger TG, Eleston DM (2011) Disturbances of pigmentation. Andrew's diseases of the skin Clinical Dermatology. (11thedn). Saunders Elsevier, Philadelphia 36:846-862.

18. Al-Waiz MM (1999) Lichen planus among Iraqi Patients:Clincoepidemiological Study. Iraq Jour of Comm Med 13: 63-66.

19. Ruiz-Maldonado R, Orozco-Covarrubias L (2008) Metabolic and systemic diseases. Dermatology. (2ndedn). Spain, ELSEVIE, 2008; 51,672.

20. Sharquie KE, Al-Bayatti AA, Al-Zaidi QM, Al-Bahar AJ (2004) Acanthosis nigricans as skin manifestation of polycystic ovarian syndrome in primary infertile female. Middle East Fertility Society J 9: 136-139.

21. Sharquie KE, Al-BayatiAA, Al-Ajeel AI, Al-Bahar AJ, Al-Nuaimy AA (2007) Free testosterone ,luteinizing hormone/follicle stimulating hormone ratio and pelvic sonography in relation to skin manifestations in patients with polycystic ovary syndrome. Saudi Med J 28:1039-1043.

22. Sharquie KE, Al-Meshhadani SA, Al-Karany ES, Al-Waiz MM, AlBayatti, et al. (2009) Serum insulin and insulin resistance in patients with acanthosis nigricans. JSSDDS $13: 11-19$.

23. Sharquie KE, Noaimi AA, Muhammed AH (2007) Acanthosis Nigricans in Iraqi Patients: Clinical, Histopathological and Therapeutic Study. Thesis for Fellowship of Iraqi Board for Medical Specializations in Dermatology and Venereology.

24. Sharquie KE, Al-Dulaimy S (1999) Postinflammatory hyperpigmentation. A Diploma Dissertation in Dermatology \& Venereology, College of Medicine, University of Baghdad.

25. Sharquie KE, Akram S (1990) Phytophotodermatitis among Iraqi patients. A Diploma Dissertation in Dermatology \& Venereology, College of Medicine, University of Baghdad.

26. de Almeida HL Jr, Jorge VM (2006) The many faces of phytophotodermatitis. Dermatol Online J 12: 8.

27. Kunachak S, Leelaudomlipi P, Wongwaisayawan S (2001) Dermabrasion: a curative treatment for melasma. Aesthetic Plast Surg 25: 114-117.

28. Katoulis AC, Stavrianeas NG, Panayiotides JG, Bozi E, Vamvasakis E, et al. (2007) Poikiloderma of Civatte: a histopathological and ultrastructural study. Dermatology 214: 177-182.

29. Seike M, Hirose Y, Ikeda M, Kodama H (2003) Coexistence of Riehl's melanosis and lichen planus. J Dermatol 30: 132-134. 